\title{
Growers follow the label: An analysis of bee-toxic pesticide use in almond orchards during bloom
}

Pesticide use data indicate that almond growers have reduced labeled bee-toxic pesticide use, but unlabeled bee-toxic agrochemicals are still applied during bloom.

by Jennie L. Durant*, Brittney K. Goodrich*, Kelly T. Chang and Evan Yoshimoto

Online: https://doi.org/10.3733/ca.2020a0030

\section{Abstract}

California almond orchards are most U.S. beekeepers' first stop on their pollination and honey production circuit, so the agrochemicals bees are exposed to in almonds can shape the vitality of their colony for the rest of the year. We explored the potential for honey bee exposure to bee-toxic agrochemicals during almond bloom by utilizing the California Department of Pesticide Regulations' Pesticide Use Report database from 1990 to 2016 . We found that overall, growers are observing the pesticide labels and reducing their use of labeled bee-toxic pesticides during almond bloom. However, we also found that insect growth regulators, fungicides and organosilicone surfactants - agrochemicals often not labeled as toxic to bees — are commonly applied during almond bloom. These agrochemicals can be sublethally or synergistically toxic to adult honey bees and bee larvae, presenting potential harm to colonies during almond pollination. Our findings demonstrate the need for a shift in the U.S. Environmental Protection Agency's labeling requirements, as well as continued communication between almond growers, pesticide applicators and beekeepers to keep colonies at a low risk of bee-toxic agrochemical exposure.
$\mathrm{M}$ anaged honey bees add an estimated $\$ 17$ billion in direct and indirect pollination services to nearly $70 \%$ of all major food crops in the United States (Calderone 2012). Yet despite their critical economic and ecological role, the current state of honey bees is precarious. In 2018, commercial beekeepers (those managing 501 or more colonies) lost over $37.5 \%$ of their colonies during winter, while stating that losses of less than $22 \%$ were economically viable (Bruckner et al. 2019). Research indicates that honey bee vulnerability is due to a nexus of stressors: parasites such as Varroa destructor mites and the gut fungus Nosema ceranea, pathogens and disease, a lack of healthy and diverse pollen resources, and exposure to bee-toxic pesticides (Goulson et al. 2015). In 2016,
An analysis of pesticide use data from 1990 to 2016 shows that San Joaquin Valley almond growers have reduced their use of labeled bee-toxic pesticides during almond bloom. However, documented bee-toxic agrochemicals without EPA precautionary statements are still commonly applied during bloom. 
commercial beekeepers in the United States attributed approximately $9 \%$ of their colony losses to pesticides (Kulhanek et al. 2017).

Each year, the majority of U.S. beekeepers truck their honey bees to California to pollinate almonds from mid-February to mid-March. California growers produce $100 \%$ of the almonds commercially grown in the United States (CDFA 2017, 113), and over $80 \%$ of global almond production (Almond Board 2017, 7). This demand has contributed to almonds' high market value and subsequent expansion from over 480,000 planted acres in 1995 to 1.3 million acres in 2018 (CDFA 2018). As the almond industry has expanded, it has also required an increasing number of honey bee colonies. The current recommendation is two colonies per acre for maximum pollination services (USDA and FCIC 2018). This meant that, in 2018, approximately 2 million colonies were required in California's Central Valley to pollinate almonds - around $81 \%$ of managed honey bee colonies in the United States (Goodrich et al. 2019).

Pollinating for the almond industry has benefits and challenges for beekeepers and their honey bees. Almond pollination fees have significantly increased over the years, and the income from almond pollination now provides over a third (33.7\%) of all beekeeper revenue in the United States (Ferrier et al. 2018, 6). Almond pollen is also high in protein (Ellis et al. 2013) and good for the development of young honey bee workers (Keller et al. 2005a and 2005b). However, the honey that bees produce while in almonds is bitter and largely unmarketable, and preparing bees for an early February pollination is labor and input intensive for beekeepers (Durant 2019). Managed colonies may also be exposed to bee-toxic agrochemicals during almond bloom that can have toxic effects on honey bees (Fisher II et al. 2017, 2018; Wade et al. 2019).

Almonds are most beekeepers' first stop on their annual pollination and honey production circuit, so the agrochemicals bees are exposed to in almond orchards can shape the vitality of their colony for the rest of the year, affecting their ability to meet future pollination contracts and earn income from honey production. To reduce pesticide exposure to honey bees, growers are encouraged by UC Integrated Pest Management (UC IPM), the California Department of Pesticide Regulation (CDPR) and the Almond Board of California (Almond Board) to primarily focus their use of insecticides during the dormant period before bloom begins in mid-February (Almond Board 2014; CDPR 2018; Pickel et al. 2004). At the same time, however, growers sometimes find it necessary to use fungicides, insect growth regulators or other pesticides during bloom - agrochemicals that can be sublethally or synergistically toxic for bees but are not labeled as such (see online technical appendix, table A).

Our objective was to trace growers' application of these chemicals during almond bloom and assess the potential risks of pesticide exposure for honey bee colonies. We evaluated growers' pesticide use in the San Joaquin Valley, the region where the greatest number of almond orchards (CDFA 2019), and subsequently bee colonies, concentrate each year (Goodrich 2017).

\section{Federal pesticide regulation}

In the United States, pesticide regulation is overseen by the U.S. Environmental Protection Agency (EPA), which reviews the product label as part of the licensing and registration process for pesticides as mandated by the Federal Insecticide, Fungicide and Rodenticide Act (FIFRA) and the Code of Federal Regulations (40 CFR, parts 150-189) (U.S. EPA 2019a). Every pesticide product is required to have a hazard and precautionary statement for environmental hazards, including risks to non-target insects (Labeling Requirements for Pesticides 2001, subpart E). The hazard statement describes the type of hazard that might be present, while the precautionary statement instructs which actions the user must take to "avoid the hazard or mitigate its effects" (Labeling Requirements for Pesticides 2001, subpart E).

To register a pesticide for outdoor use, FIFRA mandates that companies must provide EPA with reliable data on its toxicity for honey bees, including the results of an adult honey bee acute contact test (Data Requirements for Pesticides 2007, subpart G). The acute contact test is designed to determine the median lethal dose of a pesticide - either the end product formulation or active ingredient - that will kill 50\% of an experimental population of adult honey bees through a topical application of the test substance (i.e., an $\mathrm{LD}_{50}$ value) (US EPA and OCSPP 2012). After bees'

\section{In 2018, approximately} 2 million honey bee colonies were required in California's Central Valley to pollinate almonds around $81 \%$ of managed honey bee colonies in the United States.

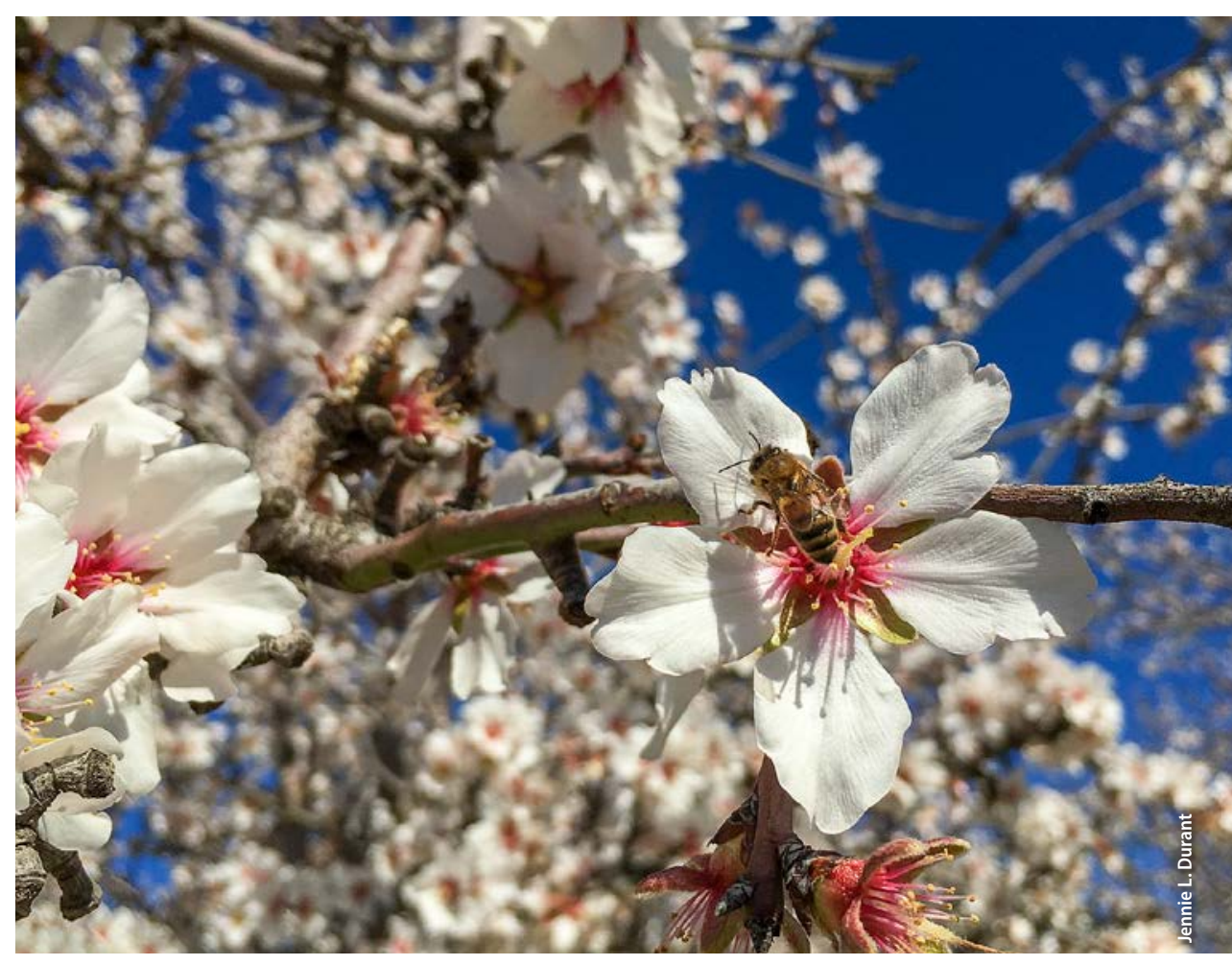




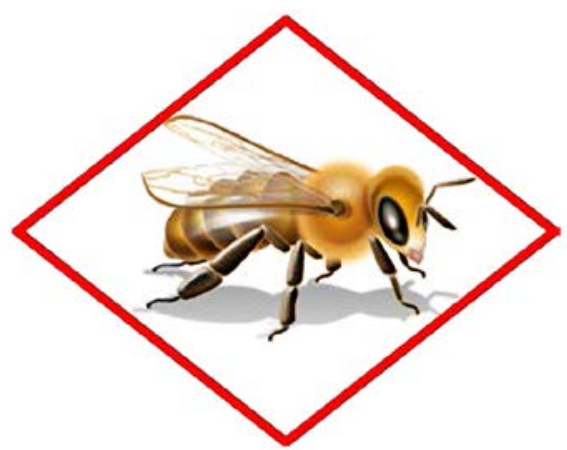

The EPA's moderate and highly toxic ratings require a "Bee Hazard" graphic on the product label.

thoraxes are exposed to the substance, bee mortality is observed for a maximum of 96 hours. If the $\mathrm{LD}_{50}$ dose is 11 micrograms $(\mu \mathrm{g})$ or more, or bees will never encounter the substance (e.g., rat poison), then the pesticide is considered essentially non-toxic to bees. If the value is between $2 \mu \mathrm{g}$ and $10.9 \mu \mathrm{g}$, the pesticide is labeled "moderately toxic", and if the $\mathrm{LD}_{50}$ dose is less than $2 \mu \mathrm{g}$, the pesticide is considered highly toxic (US EPA 2016). Both the moderate and highly toxic ratings require a "Bee Hazard" graphic on the label.

Highly and moderately toxic pesticides can have a range of effects on bees but are not the only source of high-impact exposure. These pesticides often kill bees on contact (Medrzycki et al. 2013), but poisoned bees can also become irritable and likely to sting, tremble, become paralyzed, or exhibit other abnormal behavior. In general, the symptoms occur quickly (within 96 hours) and are easy to observe. The symptoms of sublethal pesticide poisoning, which are not considered "toxic" per EPA standards, are often more complex or may take longer to become apparent. These symptoms might include decreased learning ability and foraging, decreased brood production and egg laying by the queen, or emergent bee wing deformation and stunted growth (Thompson 2003). In general, a worker bee must be able to fly, use short and long-term memory functions to communicate, care for larvae, and perform other social functions (Medrzycki et al. 2013). Determining sublethal or chronic toxicity requires different assays or test procedures to gauge the effect of the test substance on these functions, a more complex process than acute toxicity tests.

Though FIFRA only mandates the acute contact test, EPA typically requires more extensive testing as part of registration (Douglass and Steeger 2019; Housenger and Douglass 2019). Around 2016, EPA began to require the oral toxicity test, where adult bees are fed the test substance for acute toxicity, as well as a 21-day honey bee larval toxicity test (OECD 2016; US EPA 2016). EPA may also require some chronic toxicity testing in the future, depending on the active ingredient and its end use.

EPA has begun to include larval toxicity on labels when warranted, though labels do not currently include information on sublethal toxicity (US EPA 2012).
As a result, agrochemicals that are sublethally toxic to adult or larval bees may be registered without a beetoxic precautionary label. In addition, EPA only began to require the acute oral toxicity test and the 21-day larval toxicity test in 2016 (US EPA 2016). Chemicals registered before this requirement in 2016 may not have required these data and their labels may not reflect acute oral or larval toxicities.

\section{Pesticide regulation in California}

In addition to the rules imposed by EPA, California has its own authority to regulate and license pesticides, guided by FIFRA, section 24(a), and a number of California laws and regulations (CalEPA and CDPR 2015, 4). The California Environmental Protection Agency (CalEPA) and CDPR oversee pesticide enforcement in collaboration with each county's agricultural commissioner's office (CAC). If growers plan to apply a labeled "bee-toxic" or "restricted use" chemical, they are required to contact the CAC 48 hours prior to application and then notify beekeepers to give them time to move their bees, cover them or discuss an application plan that will best protect their bees. If the pesticide does not have a bee-toxic precautionary label, the grower is not required to contact the beekeeper.

This is a challenge for beekeepers, because some of the pesticides used during dormancy and bloom, such as fungicides and insect growth regulators (IGRs), have demonstrated toxicity to bees (see technical appendix, table A). Many of these chemicals tend to affect honey bee larval development, and as a result, beekeepers often do not notice damage from these agrochemicals until weeks after the application. Shortly after almond bloom ends around mid-March, beekeepers may relocate their hives for honey production, spring splitting (the process of expanding colony numbers) or for their next pollination contract. This can make it difficult to pinpoint which chemical caused the damage, and especially challenging to report it.

\section{Unlabeled agrochemical toxicity}

An additional challenge beekeepers face is that some pesticides exhibit synergistic toxicity when mixed with other agrochemicals in the sprayer tank (Fine et al. 2016; Mullin 2016; Wade et al. 2019; Zhu et al. 2014; see technical appendix, table A, for more citations). Pesticide synergy occurs when the combination of two or more active ingredients are more powerful (e.g., more toxic to bees) than the effects the chemicals would have individually (US EPA 2019b). Growers or pesticide applicators often tank mix to reduce application costs by limiting the number of times a spray rig must go through an orchard, so they might combine all the desired chemicals in one tank and spray them on one application trip. Controlled studies indicate that some insecticides and fungicides used in almond orchards 
become more toxic to bees when mixed than if the chemicals were applied separately (Fisher II et al. 2017; Wade et al. 2019). Currently, synergistic interactions are not addressed on pesticide labels. EPA is finalizing a process in which registrants are required to document whether they have any existing patent claims for synergistic activity (US EPA 2019b), but the implications of this new process for labels is unclear.

Pesticides are not the only problematic agrochemical for bees. A class of agrochemicals called organosilicone surfactants, a type of spray adjuvant, can make bee larvae more susceptible to viral pathogens and decrease olfactory learning in honey bees (Fine et al. 2016), which may have implications for honey bee foraging abilities (Ciarlo et al. 2012). Adjuvants are spray tank additives that enhance the ability of pesticide formulations to help them spread or stick to the foilage of the target plant or the surface of the target insect (US EPA and OCSPP 2015). Formulations with organosilicone surfactants are more likely to penetrate honey bees' waxy cuticle and - perhaps most importantly - can increase the toxicity of other chemicals (May et al. 2015).

Because adjuvant products "don't make pesticidal claims," they are not considered pesticides by EPA, and thus will not be labeled with a precautionary statement or tested for their bee toxicity (US EPA and OCSPP 2015). CalEPA and CDPR, however, define a spray adjuvant as a pesticide, require its registration (CalEPA and CDPR 2015, 5), and require that any applications be reported to the county agricultural commissioners' office. However, like EPA, CDPR also does not require ecotoxicology testing, including for pollinators, on adjuvant products, which means that their actual toxicity is unknown to regulatory agencies. This puts many growers, and the pesticide applicators who apply pesticides in their orchards, in a position where the labels and regulations they rely on to safely apply pesticides do not reflect their actual toxicity to bees.

\section{Methods}

To investigate grower pesticide use, we drew from CDPR's Pesticide Use Report (PUR) database for each of the eight counties in San Joaquin Valley (Fresno, Kern, Kings, Madera, Merced, San Joaquin, Stanislaus and Tulare) from 1990 to 2016 (CDPR n.d.). We statistically analyzed trends throughout the whole time period, but given the technological changes that generate new classes and formulations of pesticides, we largely focused figures and discussion on pesticide use from 2000 to 2016. To account for expanding almond acreage, we used each county's annual crop report data to gather bearing acreage of almonds by county. We divided pounds of active ingredients and applications by bearing almond acreage to adjust for increased applications over the time period due to the increased acreage.

Our analysis concentrated on agrochemical ap-

plications in almonds during almond bloom each year
(February 15 to March 15), and during the months when bees would commonly be in California either before (January 1 to February 15) or after bloom (March 15 to April 1). By January 1, 2018, roughly 761,000 colonies had already been shipped into California for almond bloom, and during the month of January 2018 another 633,000 colonies were shipped in (CDFA, unpublished data).

To obtain the pesticide toxicity and label status, we referred to the UC IPM website on "Bee Precaution Pesticide Ratings" (UC IPM n.d.) and the Pacific Northwest Extension publication "How to Reduce Bee Poisoning from Pesticides" (Hooven et al. 2016). The latter compiles commonly used pesticides and organizes them by toxicity; it also indicates pesticides which have no precautionary statements but require further data. We then conducted an extensive literature review of pesticides used during bloom that do not have precautionary labels. Table A in the technical appendix notes the effects of many of these non-acutely toxic agrochemicals on honey bees, though it is not exhaustive. We define the category of non-acutely toxic chemicals to include chemicals that peer-reviewed research indicates are sublethally or synergistically toxic to bees, but do not have an EPA acute toxicity rating. Tables B and $\mathrm{C}$ (technical appendix) show the agrochemicals analyzed in this paper.

Additionally, this paper was informed by over 81 semi-formal interviews with almond-pollinating beekeepers with operations ranging from 20 colonies to over 20,000 colonies, almond growers, researchers and extension specialists working with beekeepers and almond growers and government officials from the county agricultural commissioner's office and EPA (Durant 2019). Unless specified as "commercial beekeeper," our use of the term "beekeeper" refers to any beekeeper that pollinates almonds, of any operation size.

We analyzed historical trends using linear regression analysis. Full regression results are reported in technical appendix tables D, E and F. The regressions were performed on applications and active ingredients applied during bloom, summarized at the county level each year. The regressions measure the average trend of the dependent variable (either applications or active ingredients per acre) over the 1990-2016 time period. We supplemented the statistical trend analyses with figures and discussions that represent more recent time periods.

\section{Results of pesticide analysis}

We found that since 1990, both the bloom-time (February 15 to March 15) applications per acre and the amount per acre (pounds of active ingredient) of the pesticides listed in table B have decreased (figs. 1 and 2). Using regression analysis, both of these trends were statistically significant at the $1 \%$ level (technical appendix tables D and E). Since 1990, the amount of

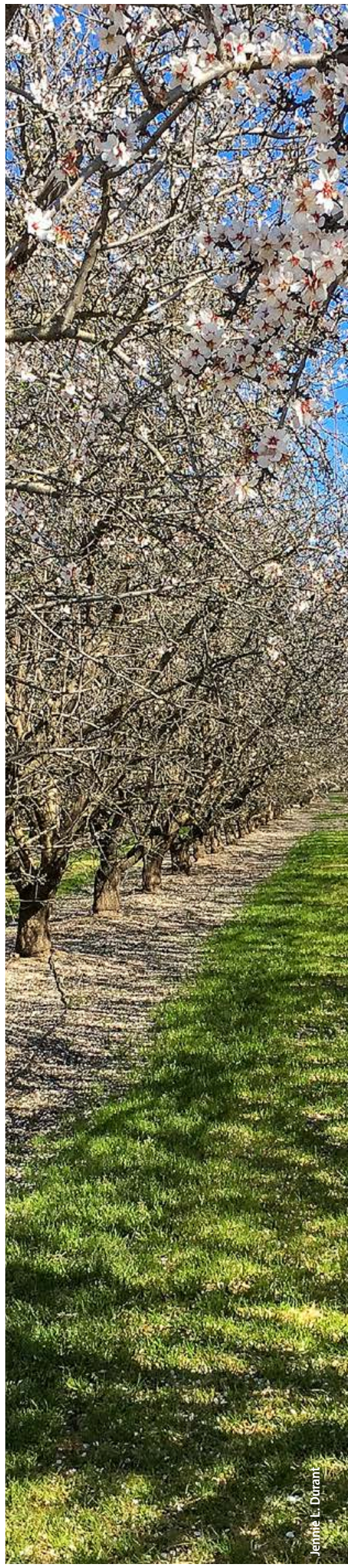


active ingredient applied per bearing acre of almonds has decreased on average across counties by 0.09 pounds per year (fig. 1). Applications per bearing acre of almonds per year have decreased on average by 0.0001 applications per year (fig. 2). The decreasing trend in applications per acre is less apparent over the 1990-2016 time period, though applications per acre since 2010 have decreased substantially. The decreasing trends in applications and active ingredient per acre vary across type and toxicity of pesticides and are discussed below.

\section{Types of agrochemicals applied}

Fungicides were the only pesticide category with a significant decrease in pounds of active ingredient applied during almond bloom over the 1990-2016 time period ( $p$-value $<0.01$; fig. 3 ). Since fungicides make up the majority of figure 3 , with herbicides being the

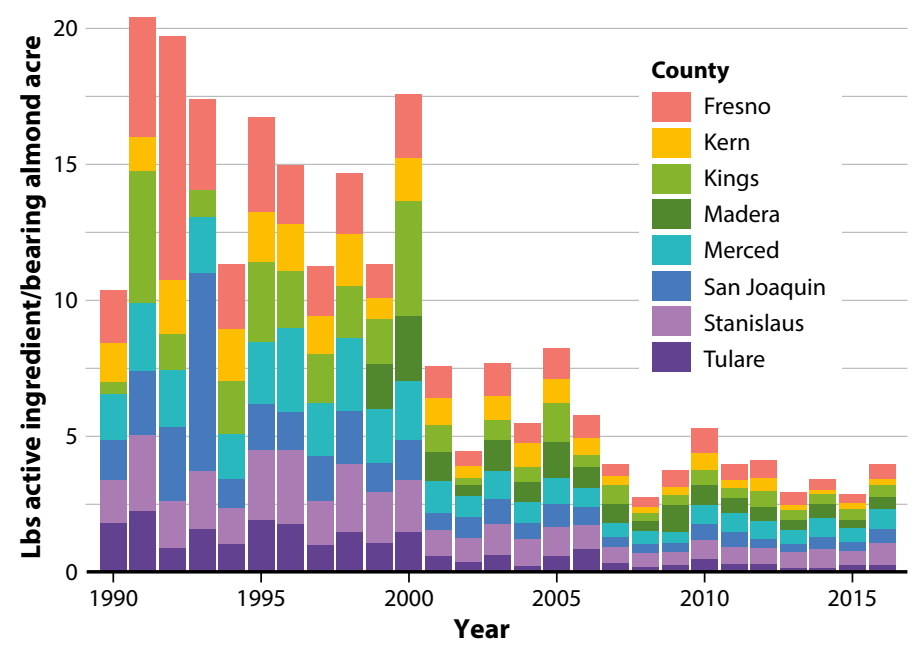

FIG. 1. Pounds of active ingredient of agrochemicals in table $B$ applied per bearing almond acre during almond bloom by county, February 15 to March 15, 1990-2016.

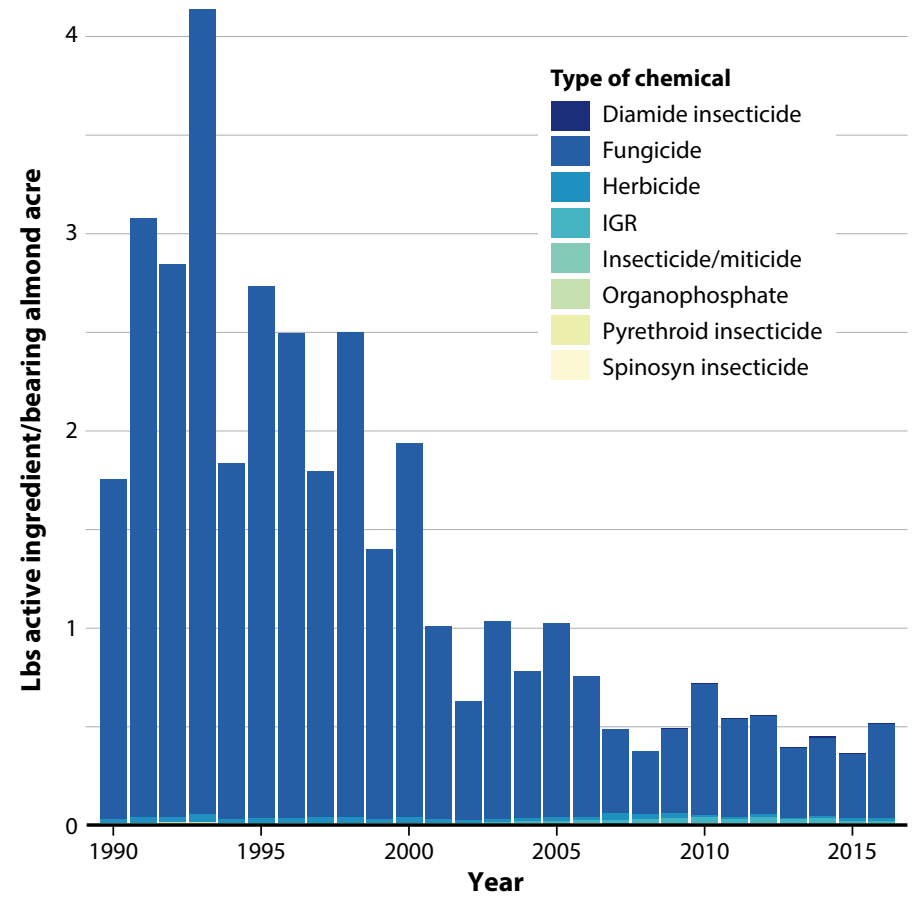

FIG. 3. Pounds of active ingredient of agrochemicals in table $B$ applied per bearing acre of almonds during bloom by type of chemical, February 15 to March 15, 1990-2016. This figure largely only represents fungicides and to a lesser extent, herbicides. Note: Listed miticides are those applied to almond orchards, not to treat Varroa mites on honey bees.

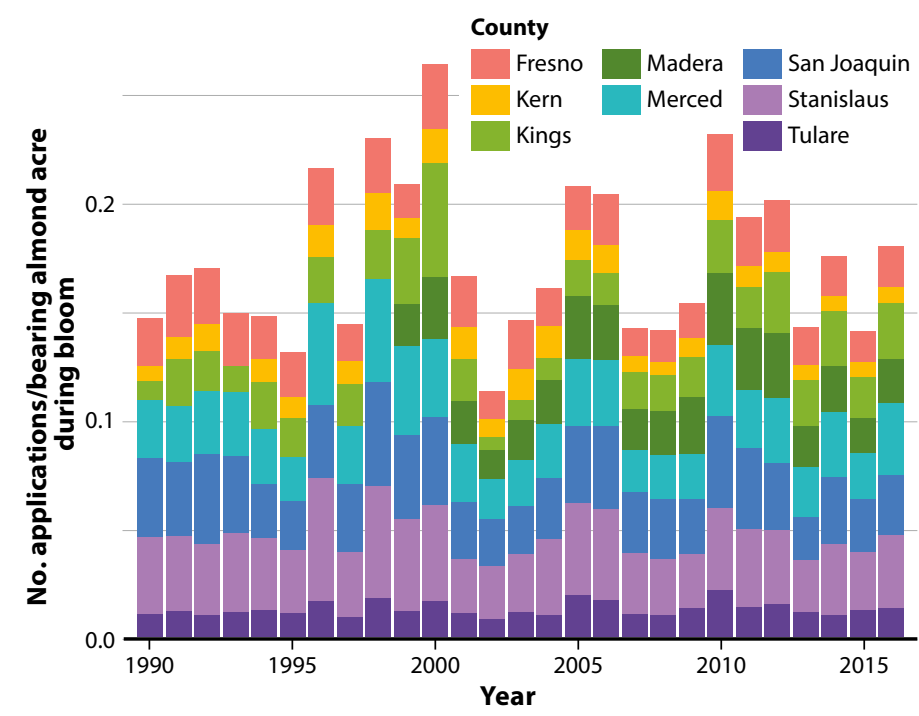

FIG. 2. Applications of all agrochemicals in table B per bearing almond acre during almond bloom by county, February 15 to March 15, 1990-2016.

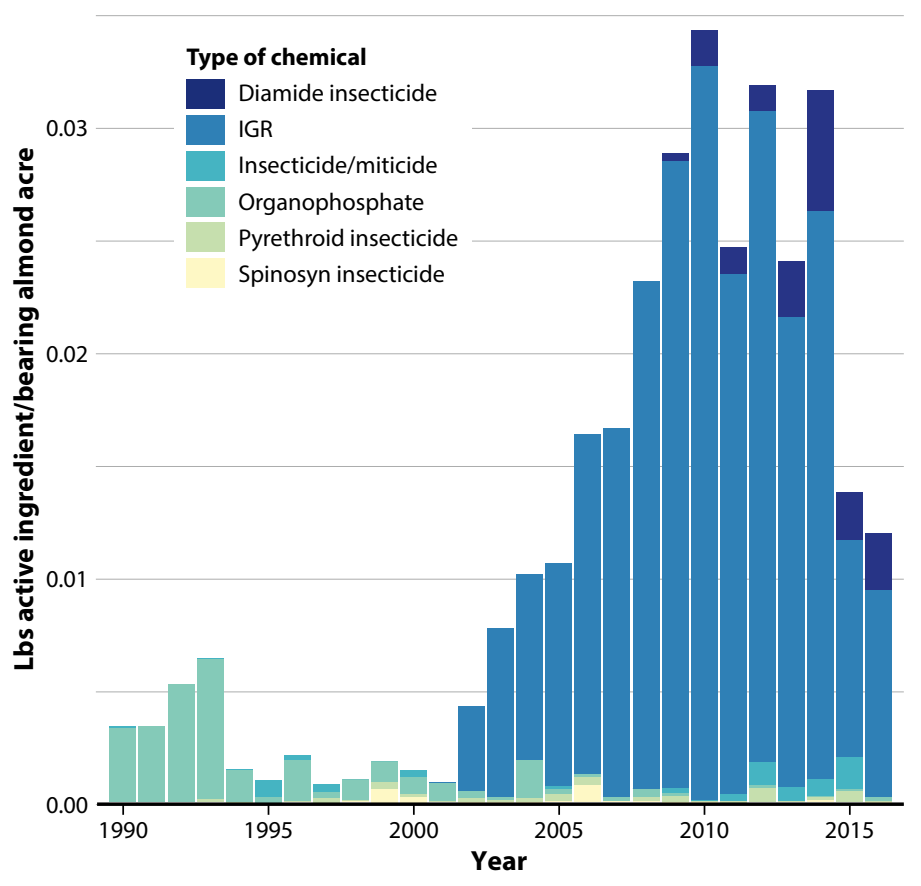

FIG. 4. Pounds of active ingredient of agrochemicals in table B applied per bearing acre of almonds during bloom by type of chemical, without fungicides and herbicides, February 15 to March 15, 1990-2016. Note: Listed miticides are those applied to almond orchards, not to treat Varroa mites on honey bees. 
next largest category, Figure 4 shows the pounds of active ingredient applied by type of chemical, excluding fungicides and herbicides. From figure 4, it is apparent that there was a switch in the late 1990s from the use of highly toxic insecticides, organophosphates and pyrethroids, to IGRs. The use of IGRs increased from 2002 to 2010, when organophosphate and pyrethroid usage began to decrease.

\section{Time periods, toxicity of applications}

Highly toxic chemicals did not have statistically significant trends in applications or active ingredient applied per acre over the 1990-2016 time period (technical appendix tables D and E). Since 1990, pounds per acre of active ingredients applied have decreased on average by $0.087(p<0.01)$ and $0.007(p<0.10)$ for non-acutely toxic and moderately toxic chemicals, respectively. There was no statistically significant trend in applications per acre of non-acutely toxic chemicals since 1990, while applications per acre of moderately toxic chemicals have decreased $(p<0.01)$. Consistent with the absence of a long-term trend, highly toxic chemicals have been applied at low levels per acre during almond bloom since the year 2000, so there was little room to decrease this amount over time (fig. 5). Moderately toxic chemicals were applied at slightly higher levels per acre than highly toxic ones and saw a slight decrease between 2000 and 2016. Non-acutely toxic chemicals were applied at relatively high levels per acre beginning in 2000, but have decreased over time (fig. 5).

Table 1 shows the average number of agrochemical applications per day in the San Joaquin Valley for

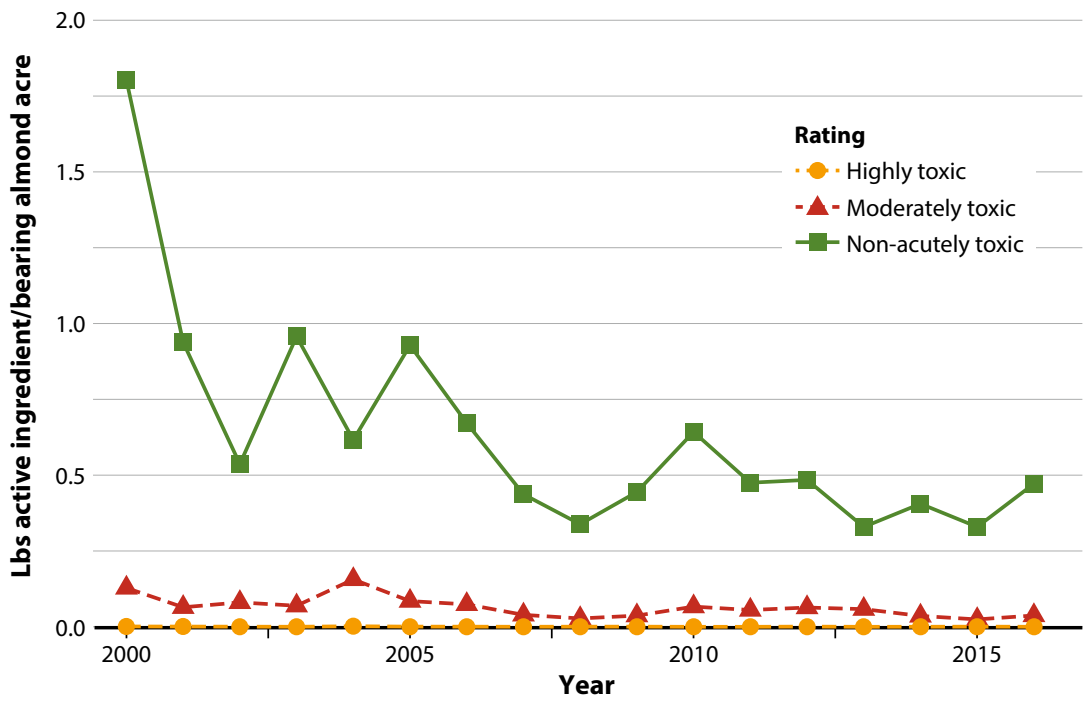

FIG. 5. Pounds of active ingredient of agrochemicals in table $B$ applied per bearing almond acre during almond bloom by bee-toxicity rating, February 15 to March 15, 2000-2016. Note: Non-acutely toxic includes sublethally and synergistically bee-toxic chemicals (table A).

TABLE 1. Mean number of total applications per day in San Joaquin Valley for agrochemicals in table B by toxicity rating and timing, 2010-2016

\begin{tabular}{|l|c|c|c|}
\hline & \multicolumn{3}{|c|}{ Mean no. of total applications per day } \\
\hline Bee toxicity rating & $\begin{array}{c}\text { Pre-bloom } \\
\text { (Jan 1-Feb 14) }\end{array}$ & $\begin{array}{c}\text { Bloom } \\
\text { (Feb 15-Mar 15) }\end{array}$ & $\begin{array}{c}\text { Post-bloom } \\
\text { (Mar 16-Apr1) }\end{array}$ \\
\hline Highly toxic & 49 & 1 & 10 \\
\hline Moderately toxic & 31 & 21 & 3 \\
\hline Non-acutely toxic & 51 & 594 & 276 \\
\hline
\end{tabular}

Note: Non-acutely toxic includes sublethally and synergistically bee-toxic chemicals (online appendix table A).

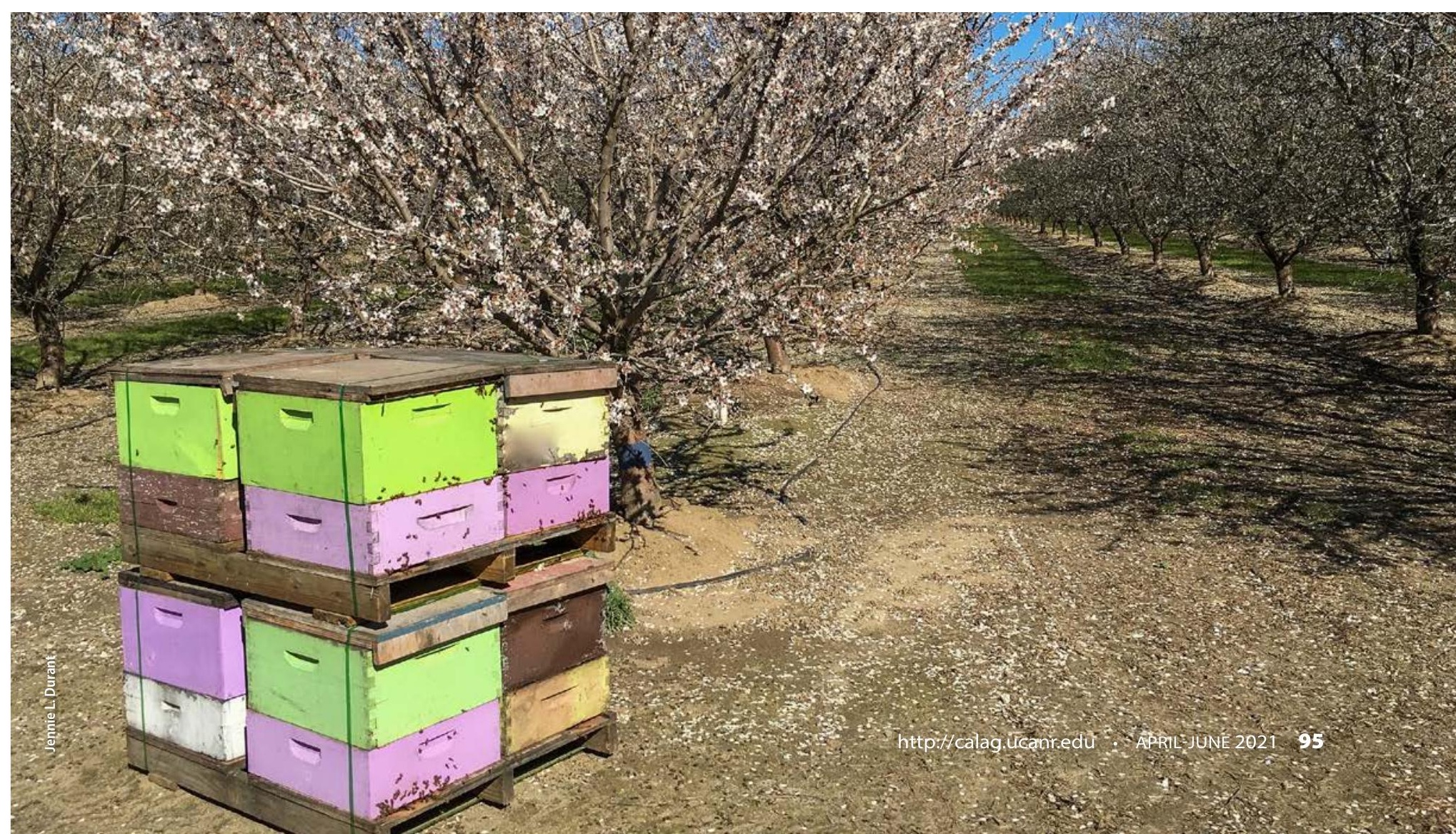


the years 2010 to 2016, separated by bee-toxicity rating (highly toxic, moderately toxic, and non-acutely toxic) and timing with respect to almond bloom. This table is not adjusted for almond acreage, and is meant to broadly reflect the growers' decisions regarding pre-, during- and post-bloom applications. The most harmful chemicals are applied infrequently when bees are in almond orchards during bloom, on average one application per day. However, there are still some applications of highly toxic and moderately toxic pesticides prior to bloom. Non-acutely toxic chemicals (primarily fungicides, IGRs and herbicides) are often applied within the almond bloom time period, and it is clear that non-acutely toxic applications compose the majority of all chemical applications during bloom with an average of 594 applications per day.

Figures 6 and 7 show histograms of chemical applications with and without a bee-toxic precautionary statement, respectively. We found that chemicals with precautionary statements were applied before bloom, but rarely during the bloom period (fig. 6). On the other hand, chemicals without precautionary statements were frequently applied during bloom (fig. 7). These results highlight one of our key findings, that growers are following the label during bloom, but are also applying agrochemicals without precautionary statements (which are sometimes bee-toxic) while bees are pollinating almonds.

Our results indicate there is no noticeable trend with applications per acre of pesticides with no precautionary statement; however, the trend in pounds per acre of active ingredient since 1990 is negative and statistically significant ( $p<0.01$; fig. 8 ). The average number of applications per acre with chemicals labeled with precautionary statements has decreased over time $(p<$ 0.01 ), though there was no statistically significant trend in active ingredient per acre. Declines in applications per acre during bloom may be due to a greater awareness among almond growers and pesticide applicators

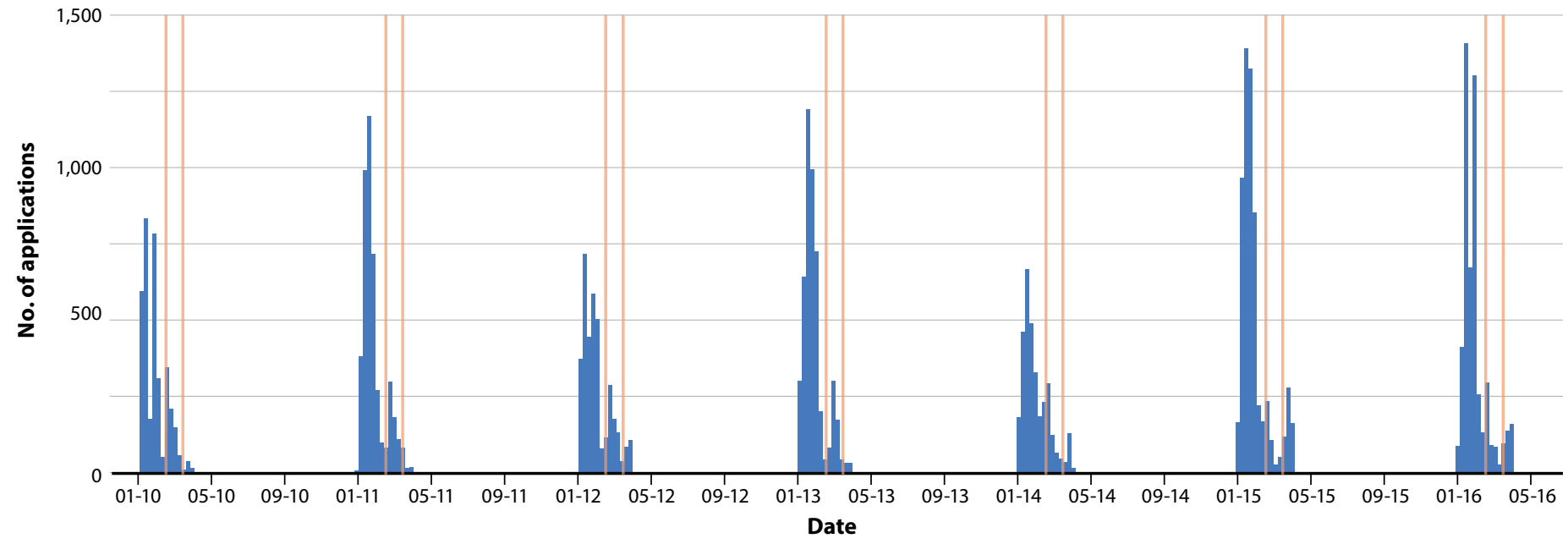

FIG. 6. Histogram of weekly applications of agrochemicals in table B with precautionary statements (almond bloom period highlighted), January 1 to April 1, 2010-2016.

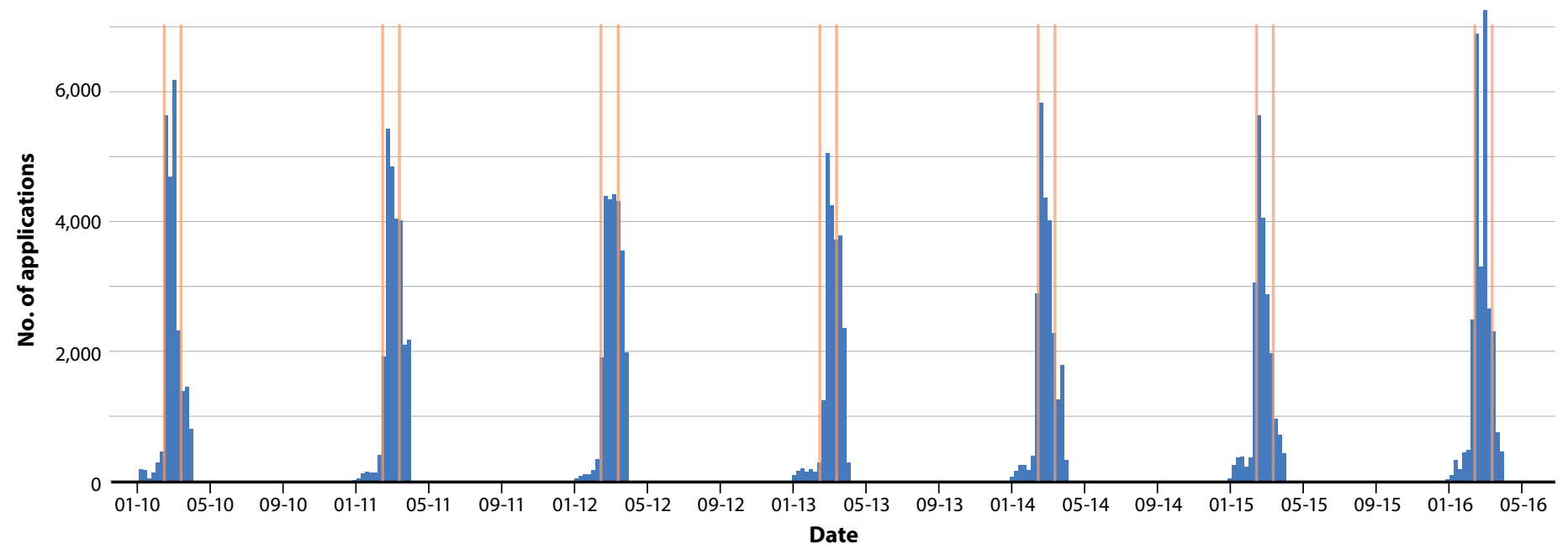

FIG. 7. Histogram of weekly applications of agrochemicals in table B without precautionary statements (almond bloom period highlighted), January 1 to April 1, 2010-2016. 
that these pesticides can be toxic to bees, or it may just indicate sensitivity to label instructions.

\section{Organosilicone surfactant applications}

Since 1990, there has been an upward trend in organosilicone surfactant use in pounds per acre during almond bloom $(p<0.01)$; this seems to vary by toxicity rating (technical appendix table F). Over the 1990-2016 period, the increasing trend for sublethal organosilicone surfactants was more than that of surfactants with unknown toxicity. Figures 9 and 10 suggest that organosilicone surfactant use per bearing acre of almonds during bloom has increased in recent years, especially in application levels of organosilicone surfactants that have unknown toxicity to bees. The majority of organosilicone surfactants applied may have sublethal toxicity to bees, though more research needs to be conducted to understand the depth and breadth of their toxicity (Chen et al. 2018; Mullin et al. 2016). It would be interesting to know why the use of organosilicone surfactants was so low in 2012. This information might provide useful insights into tactics that would decrease the use of these chemicals.

\section{Study limitations}

One limitation of our analysis is that we did not analyze the time of day agrochemicals were applied. The time of application can make a big difference in bee toxicity due to honey bees' typical foraging behavior. This is a knowledge gap that limits our ability to interpret our findings. For example, bee-toxic agrochemical use could be rising, but if growers are applying these chemicals only in the late afternoon or evening then it may not be problematic for bees, who typically stop foraging by that time. Timings of agrochemical applications are included in the PUR data and are an area for future exploration.

A second limitation is that this study only looks at agrochemical applications by almond growers, while many beekeepers express concern about pesticide

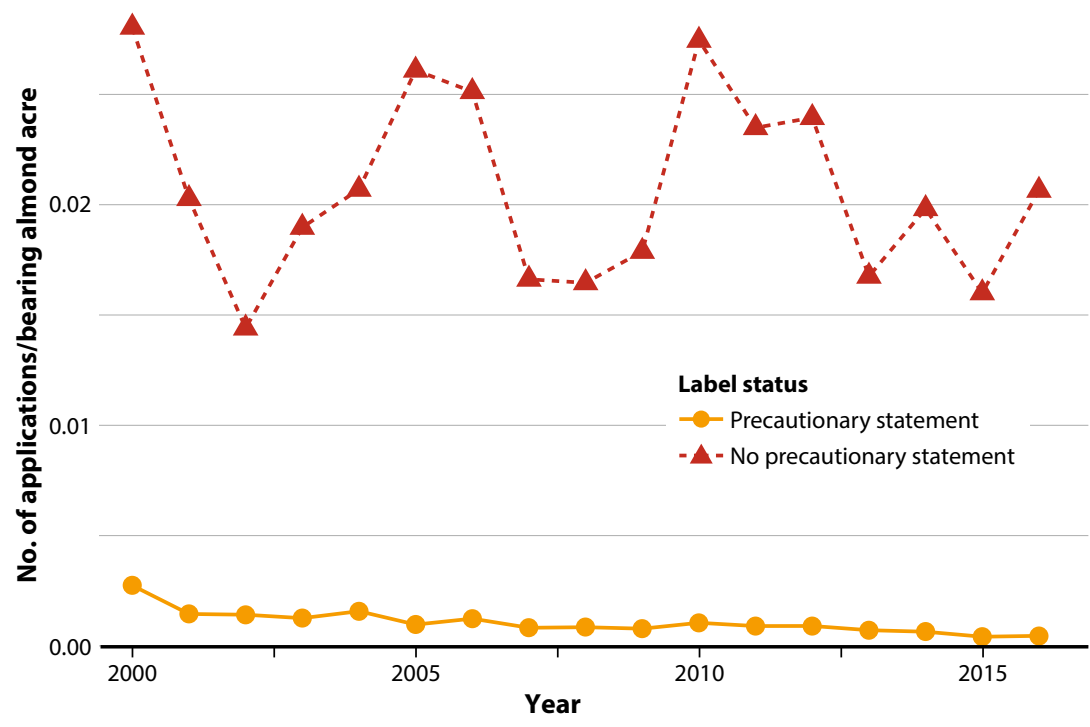

FIG. 8. Applications per bearing almond acre of agrochemicals in table $B$ during almond bloom by label status, February 15 to March 15, 2000-2016.

damage from neighboring crops such as stone fruits or alfalfa. This study does not address agrochemical use from neighboring crops in the region, which is another area for future research. A third limitation is that we do not know definitively if the decreasing trends in agrochemical use is due to the increased toxicity of the formulation, which then requires less pounds per acre for each application. We suspect this is the case, but is outside the scope of this study and another area for future research.

\section{Steps for mitigating bee losses}

To address the use of sublethally and synergistically bee-toxic pesticides during almond bloom due to the knowledge gap in the EPA labeling system, beekeepers, extension specialists, the Almond Board, EPA and CDPR jointly crafted and publicized a set of Honey Bee Best Management Practices (Bee BMPs) in 2014 (Almond Board 2014). The Bee BMPs have four core

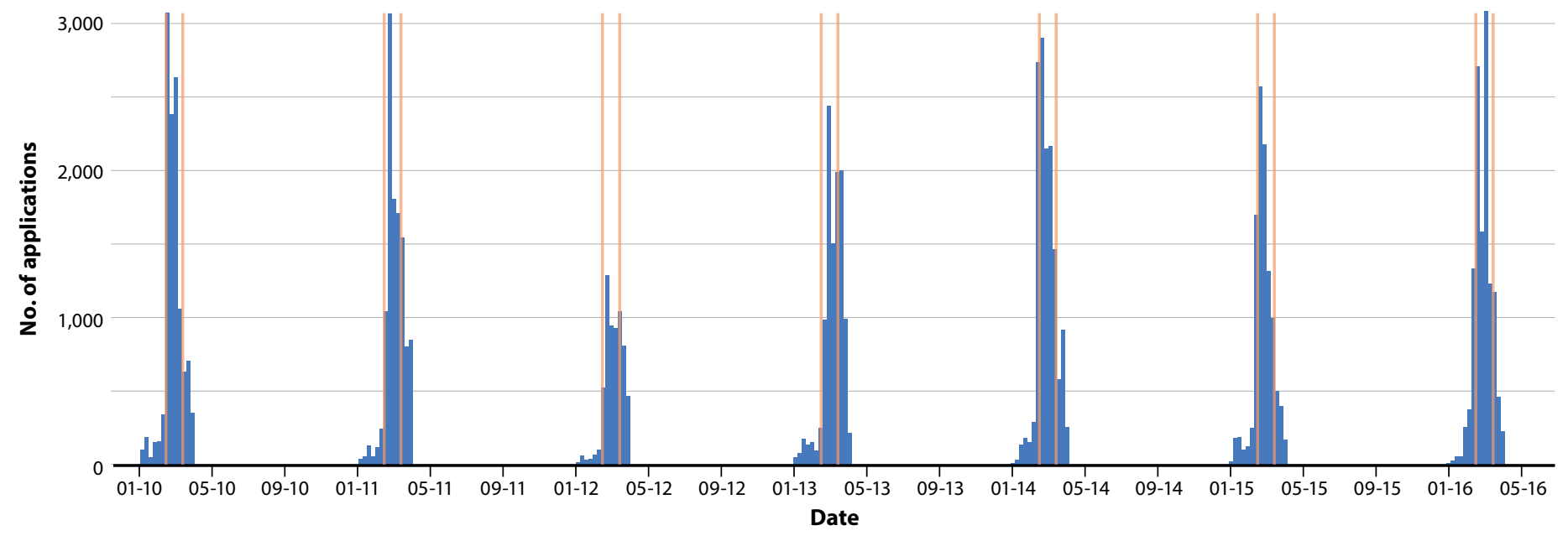

FIG. 9. Histogram of weekly applications of organosilicone surfactants in table C (almond bloom period highlighted), January 1 to April 1, $2010-2016$. 


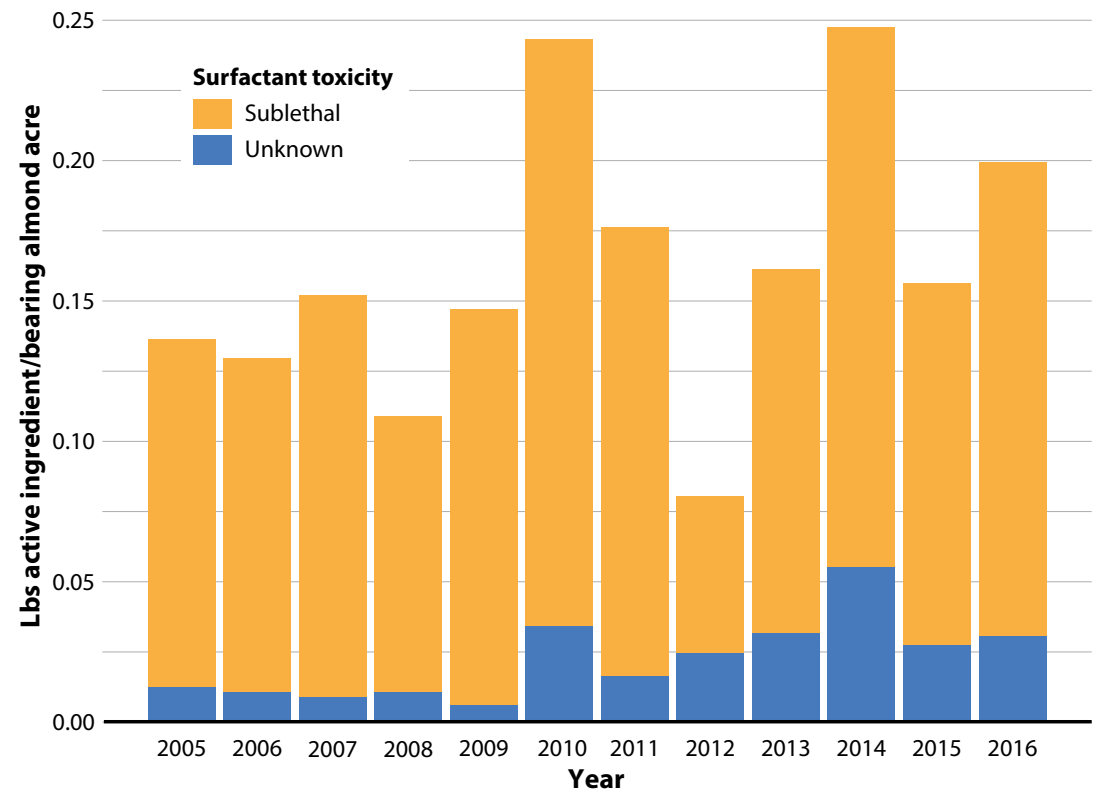

FIG. 10. Pounds of organosilicone surfactant (table $C$ ) applied per bearing acre of almonds during bloom by toxicity rating, February 15-March 15, 2005-2016.

precautions: (1) maintain communication between all parties on the specifics of pesticide application, specifically beekeepers and/or bee brokers, pesticide control applicators, farm managers and land owners; (2) only spray fungicides in the late afternoon or evening; (3) avoid tank-mixing products during bloom because some agrochemicals might have synergistic toxicities for honey bees and (4) avoid applying all insecticides during bloom. The dataset in this paper only reflects 2 years (2015-2016) of grower pesticide practices after the introduction of the Bee BMPs in 2014, so we do not attempt to make conclusions about the efficacy of its dissemination and the adoption rate of the BMPs. This would be an interesting topic for future research.

In addition to our finding on bloom-time applications of chemicals, we found that many bee-toxic pesticides are applied in January, the month before almond bloom (table 1). This is problematic for beekeepers, given that many beekeepers store their colonies in or near almond orchards over winter and the remaining colonies usually arrive by the beginning to middle of January. The applications of highly toxic and moderately toxic pesticides prior to bloom (fig. 6) may still have an impact on these colonies, and may deter beekeepers from bringing colonies into California early. This may have some unintended consequences for almond growers: in years when almonds bloom earlier than normal, and/or if a large number of beekeepers delay entry into California creating bottlenecks at California border protection stations, growers may not have all the colonies needed for adequate pollination of early blooming varieties.

Other efforts aim to facilitate better communication around pesticides between beekeepers, growers and the counties. In 2014, the Almond Board began disseminating UC Cooperative Extension research demonstrating the efficacy of insecticide applications outside of almond bloom (Almond Board 2014, 4). In 2017, a coalition of stakeholders led by the California Association of Pesticide Advisors and the County Agricultural Commissioners and Sealers Association partnered to create the BeeWhere program (https:// beewhere.calagpermits.org/). Launched in 2019, BeeWhere offers an online portal with a GIS mapping system where beekeepers can register their hives with the county, so growers and pesticide applicators can notify them before an agrochemical spray. Beekeepers and almond growers may also consider mitigating issues caused by pesticide damage through the use of clauses in their almond pollination contracts. In fact, in a survey of growers attending the 2015 Almond Conference, roughly $30 \%$ of respondents included pesticide clauses in their pollination contracts (Goodrich 2017).

Factors impacting honey bee colony health during almond pollination can have a major influence on bee health throughout the United States for the remainder of the year, and are important to trace given honey bees' crucial role in our agricultural system. Our findings suggest that changing EPA labeling requirements to include sublethally and synergistically bee-toxic agrochemicals, registering adjuvants as pesticides with the EPA and requiring larval and chronic toxicity tests as part of this registration, and growers' full adoption of the Almond Board's Bee BMPs, may all be important steps toward improving bee health. CA

\footnotetext{
* J.L. Durant and B.K. Goodrich are equal first authors. J.L. Durant is USDA-NIFA postdoctoral fellow at UC Davis and University of Oregon; B.K. Goodrich is a UC Cooperative Extension Specialist at UC Davis; and K.T. Chang and E. Yoshimoto were student researchers at UC Berkeley while the research was conducted.

This research was supported by the USDA National Institute of Food and Agriculture NIFA fellowship, project \#1019243.
} 


\section{References}

Almond Board. 2014. Honey Bee Best Management Practices for California Almonds. Almond Board of California. www. almonds.com/sites/default/ files/honey_bee_best_management_practices_for_ca almonds\%5B1\%5D.pdf

Almond Board. 2017. Almond Almanac 2017: Annual Report. Almond Board of California. http://newsroom.almonds.com/ sites/default/files/pdf_file/Almond Almanac 2017.pdf

Bruckner S, Steinhauer N, Aurell SD, et al. 2019. Honey Bee Colony Losses 2018-2019: Preliminary Results. Bee Informed Partnership. https://beeinformed.org/results/2018-2019/

Calderone NW. 2012. Insect pollinated crops, insect pollinators and US agriculture: Trend analysis of aggregate data for the period 1992-2009. PLOS ONE 7(5):1-27. https:// doi.org/10.1371/journal. pone.0037235

[CDFA] California Department of Food and Agriculture. 2017 California Agricultural Statistic Review (2016-2017). www.cdfa. ca.gov/statistics/PDFs/201718AgReport.pdf

CDFA. 2018a. 2017 California Almond Acreage Report. Sacramento, CA: California Department of Food and Agriculture. www.nass.usda.gov/ Statistics_by_State/California/ Publications/Specialty_and_ Other_Releases/Almond/ Acreage/201804almac.pdf

CDFA. 2019. 2018 California Almond Acreage Report. California Department of Food and Agriculture. www.nass.usda. gov/Statistics_by_State/California/Publications/Fruits and Nuts/2017/201704almac.pdf [CDPR] California Department of Pesticide Regulation. n.d. California Pesticide Information Portal (CaIPIP). https://calpip. cdpr.ca.gov/main.cfm CDPR. 2018. California's Managed Pollinator Protection Plan-Mp3. CA Department of Pesticide Regulation. www.cdpr. ca.gov/docs/enforce/pollinators/index.htm

[CalEPA] California Environmental Protection Agency and CDPR. 2015. A Guide for Pesticide Registrants. Sacramento, CA: California Environmental Protection Agency, CA Department of Pesticide Regulation.
Chen J, Fine JD, Mullin CA. 2018. Are organosilicon surfactants safe for bees or humans? Sc Total Environ 612:415-21. https://doi.org/10.1016/j.scitotenv.2017.08.175

CiarloTJ, Mullin CA, Frazier J Schmehl DR. 2012. Learning impairment in honey bees caused by agricultural spray adjuvants. Edited by Guy Smagghe. PLOS ONE 7(7):e40848. https://doi.org/10.1371/journal. pone.0040848

Data Requirements for Pesticides. 2007. Data Requirements for Pesticides, 40 CFR 158. www. ecfr.gov/cgi-bin/text-idx?SID= 738c16c85042ce20aec41a65f a12977e\&node $=40: 24 \cdot 0 \cdot 1 \cdot 1.9 \&$ rgn=div 5

Douglass C, Steeger T. 2019. Assessing pesticide risks to bees at national level: Processes and challenges. In Ecological Society of America 2019 Annual Meet ing. Louisville, KY: Ecological Society of America. https://esa. confexcom/esa/2019/meetingapp.cgi/Person/83558

Durant JL. 2019. Bitter Honey: A Political Ecology of Honey Bee Declines. UC Berkeley. https://escholarship.org/uc/ item/20f1f816

Ellis A, Ellis JD, O'Malley M, et al. 2013. The benefits of pollen to honey bees. IFAS Extension ENY 152:1-3. https://edis.ifas.ufl.edu/ pdffiles/IN/IN86800.pdf

Ferrier PM, Rucker RR, Thurman WN, Burgett M. 2018. Economic Effects and Responses to Changes in Honey Bee Health. ERS Report 246. Economic Research Service, U.S. Department of Agriculture. www.ers. usda.gov

Fine JD, Cox-Foster DL, Mullin CA. 2016. An inert pesticide adjuvant synergizes viral pathogenicity and mortality in honey bee larvae. Nature 7:40499. https://doi.org/10.1038/ srep40499

Fisher II A, Coleman C, Hoffmann C, et al. 2017. The synergistic effects of almond protection fungicides on honey bee (Hymenoptera: Apidae) forager survival. J Econ Entomol 110(3):802-8. https://doi. org/10.1093/jee/tox031
Fisher II A, Colman C, Hoffmann C, et al. 2018. The effects of the insect growth regulators methoxyfenozide and pyriproxyfen and the acaricide bifenazate on honey bee (Hymenoptera: Apidae) forager survival. Apiculture and Social Insects 111(2):510-

16. https://doi.org/10.1093/jee/ tox347

Goodrich B. 2017. The California Almond Pollination Market: Contracts and Honey Bee Colony Health. UC Davis. https://search.proquest.com/ docview/1992171206?pqorigsite $=$ gscholar

Goodrich B, Williams JC, Goodhue RE. 2019. The great bee migration: Supply analysis of honey bee colony shipments into California for almond polination services. Am J Agr Econ 101(5):1353-72. https://doi. org/10.1093/ajae/aaz046

Goulson D, Nicholls E, Botías C, Rotheray EL. 2015. Bee declines driven by combined stress from parasites, pesticides, and lack of flowers. Science 347:1255957. https://doi.org/10.1126/science.1255957

Hooven L, Sagili R, Johansen E. 2016. PNW 591: How to Reduce Bee Poisoning from Pesticides. Oregon State University, University of Idaho, Washington State University. https://catalog. extension.oregonstate.edu/ sites/catalog/files/project/pdf/ pnw591.pd

Housenger J, Douglass C. 2019. Regulatory Landscape and Insect Control: A Case Study of Neonics. In Ecological Society of America 2019 Annual Meeting. Louisville, KY: Ecological Society of America. https://esa.confex. com/esa/2019/meetingapp.cgi/ Person/83558

Keller I, Fluri P, Imdorf A. 2005a.

Pollen nutrition and colony development in honey bees: Part I. Bee World 86(1):3-10. https://doi.org/10.1080/00057 72X.2005.11099641

Keller I, Fluri P, Imdorf A. 2005b. Pollen nutrition and colony development in honey bees: Part II. Bee World 86(2):27-34 https://doi.org/10.1080/00057 $72 X .2005 .11099650$

Kulhanek K, Steinhauer N, Rennich $\mathrm{K}$, et al. 2017. A national survey of managed honey bee 2015-2016 annual colony osses in the USA. J Apicult Res 56(4):328-40. https://doi.org/10. 1080/00218839.2017.1344496
Labeling Requirements for Pesticides. 2001. Labeling Requirements for Pesticides and Devices, 40 CFR 156. www.ecfr. gov/cgi-bin/text-idx?SID=a6649 3222ba05a6914d6e5bfb47f867 $6 \& m c=$ true $\&$ node $=p t 40.26 .156$ \&rgn=div5\#se40.26.156_110

May E, Wilson J, Isaacs R. 2015. Minimizing pesticide risk to bees in fruit crops. Michegan State University, Department of Entomology. Extension Bulletin E3245. May 2015. http:// msue.anr.msu.edu/uploads/ resources/pdfs/Minimizing_Pes ticide_Risk_to_Bees_in_Fruit_ Crops_(E3245).pdf

Medrzycki P, Giffard H, Aupinel P et al. 2013. Standard methods for toxicology research in Apis mellifera. J Apicult Res 52:1-60. https://doi.org/10.3896/

IBRA.1.52.4.14

Mullin CA, Fine JD, Reynolds RD, Frazier MT. 2016. Toxicological risks of agrochemical spray adjuvants: Organosilicone surfactants may not be safe. Front Public Health 4:92. https://doi. org/10.3389/fpubh.2016.00092

[OECD] Organization for Economic Co-Operation and

Development. 2016. Guidance Document on Honey Bee Larval Toxicity Test Follow ing Repeated Exposure. Paris, France: The Organization for Economic Co-Operation and Development. https://one. oecd.org/document/ENV/JM MONO(2016)34/en/pdf

Pickel C, Bentley WJ, Connell JH, et al. 2004. Seasonal Guide to Environmentally Responsible Pest Management Practices in Almonds. Oakland, CA: UC Agriculture and Natural Resources. http://anrcatalog.ucdavis.edu

Thompson HM. 2003. Behavioural effects of pesticides in bees - Their potential for use in risk assessment. Ecotoxicology 12(1-4):317-30. https://doi. org/10.1023/A:1022575315413

[UC IPM] UC Integrated Pest Management Program. n.d. Bee Precaution Pesticide Ratings. https://www2.ipm.ucanr. edu/beeprecaution/ (accessed March 20, 2020).

[USDA] US Department of Agriculture and [FCIC] Federa Crop Insurance Corporation. 2018. Almond Loss Adjustment Standards Handbook: 2019 and Succeeding Crop Years. www.rma.usda.gov/-/media/ RMAweb/Handbooks/LossAdjustment-Standards---25000/ Almonds/2019-25020-AlmondLoss-Adjustment.ashx

US EPA [US Environmenta Protection Agency]. 2012. Environmental Hazards. In Label Review Manual. Washington, D.C.: US Environmental Protection Agency. www.epa.gov/sites/ production/files/2015-03/documents/chap-08-sep-2012.pdf

US EPA. 2016. Guidance on Exposure and Effects Testing for Assessing Risks to Bees. US Environmental Protection Agency. www.epa.gov/sites/production/ files/2016-07/documents/guidance-exposure-effects-testing- 